\title{
Desempenho de cordeiras em pastagens de azevém e de milheto sob suplementação
}

\section{Denise Adelaide Gomes Elejalde ${ }^{1}$, Marta Gomes da Rocha ${ }^{2}$, Carolina Bremm ${ }^{1}$, Daniele Gindri Camargo ${ }^{1}$ Cleber Cassol Pires $^{2}$, Renato Alves de Oliveira Neto ${ }^{3}$}

\footnotetext{
1 Programa Pós-graduação em Zootecnia, Universidade, Federal de Santa Maria, RS.

2 Departamento de Zootecnia, Universidade Federal de Santa Maria, RS.

${ }^{3}$ Curso de Zootecnia - UFSM.
}

RESUMO - Avaliou-se o desempenho de cordeiras em pastagens de azevém (Lolium multiflorum Lam.) e de milheto (Pennisetum americanum L. Leeke) como alimento exclusivo ou com suplementação diária com ração comercial na proporção de 0,$5 ; 1,0$ e $1,5 \%$ do peso corporal (PC). O método de pastejo utilizado foi o de lotação contínua com taxa de lotação variável. As cordeiras em pastagem de azevém com suplementação nos níveis de 0,5 e $1,5 \%$ do PC apresentaram maior ganho médio diário. Independentemente do nível, a suplementação em pastagem de azevém promoveu o maior ganho de peso por área. Na pastagem de milheto, o ganho médio diário, o ganho de peso por área e o escore de condição corporal foram maiores nas cordeiras sob suplementação. A estrutura de pastagens de azevém e de milheto não é influenciada pela oferta de suplemento aos animais. A utilização da pastagem de azevém nos períodos pré e pós-desmama, associada à suplementação nos níveis de 0,5 a $1,5 \%$ do peso vivo em pastagem de milheto, permite que cordeiras apresentem peso e escore de condição corporal adequados para o acasalamento aos 9 meses de idade.

Palavras-chave: escore de condição corporal, ganho médio diário, Lolium multiflorum, Pennisetum americanum, taxa de lotação

\section{Performance of female lambs on Italian ryegrass and pearl millet pastures under supplement levels}

\begin{abstract}
It was evaluated the performance of female lambs on cultivated pastures of Italian ryegrass (Lolium multiflorum Lam.) and pearl millet (Pennisetum americanum (L.) Leeke) as exclusive food or as daily supplementation with commercial feed at the ratio of $0.5,1.0$ and $1.5 \%$ of the body weight. The used grazing method was continuous with variable stocking. Female lambs on Italian ryegrass pasture supplemented with 0.5 and $1.5 \%$ of body weight presented greater average daily gain. Regardless to the level, supplementation on Italian ryegrass pasture promoted the highest weight gain per area. In pearl millet pasture, the daily weight gain, the weight gain per area and body condition score were higher for the lambs under supplementation. The structure of Italian ryegrass and pearl millet pastures is not affected by the offer of supplement to the animals. The use of Italian ryegrass pasture during pre and post weaning periods associated to the supplementation at the levels of 0.5 and $1.5 \%$ of body weight on pearl millet pasture allows lambs to show weight and body condition score fitted for mating at nine months of age.
\end{abstract}

Key Words: average daily gain, body condition score, Lolium multiflorum, Pennisetum americanum, stocking rate

\section{Introdução}

A ovinocultura é uma atividade tradicional no Rio Grande do Sul, com aproximadamente um quarto do rebanho ovino brasileiro (ANUALPEC, 2006). A ineficiência produtiva da atividade é histórica e, juntamente com a falta apoio aos produtores, constitui um desafio tornar a criação de ovinos mais rentável.
Melhorar a eficiência reprodutiva do rebanho, por meio do aumento do número de cordeiros desmamados por fêmea/ano, é uma meta na produção de cordeiros (Ribeiro et al., 2002). Ovelhas acasaladas pela primeira vez quando cordeiras produzem mais quilogramas de cordeiros durante sua vida que aquelas acasaladas pela primeira vez aos 18 meses de idade (Southan et al., 1971). No Rio Grande do Sul, em sistemas tradicionais de criação, as cordeiras de

Recebido em 19/8/2008 e aprovado em 23/4/2009.

Correspondências devem ser enviadas para:mgdarocha@gmail.com 
reposição não atingem condição corporal adequada para o acasalamento no primeiro ano de vida (COE, 1991).

O nível nutricional é importante para o início da puberdade em cordeiras, pois o fato de deixarem de ganhar $100 \mathrm{~g} /$ dia na fase de recria ocasiona atraso de um ano em sua vida produtiva (Castro, 2002). Um plano alimentar com adequado nível nutricional entre a desmama e o acasalamento permite que o primeiro parto ocorra por volta de um ano de vida.

A utilização de pastagens cultivadas é uma prática eficiente e de baixo custo para fornecer o aporte nutricional necessário para a redução da idade de acasalamento. As espécies forrageiras anuais com maior potencial para serem utilizadas por cordeiras, por sua adaptação às condições de clima e solo do Rio Grande do Sul, são o azevém (Lolium multiflorum Lam), no período de inverno/primavera, e o milheto (Pennisetum americanum L. Leeke), no período de verão.

O fornecimento de suplementos para cordeiras em pastejo é uma estratégia para aumentar a taxa de lotação, reduzir riscos climáticos e equilibrar a relação energia/ proteína na dieta dos animais. Além disso, o aumento na quantidade total de matéria seca consumida pelos animais sob suplementação pode melhorar o ganho individual.

Este trabalho foi conduzido a partir da hipótes de que, em pastagens de azevém e milheto, o fornecimento de suplemento a cordeiras na fase de cria e recria, respectivamente, pode alterar a estrutura do pasto e possibilitar que essas cordeiras apresentem peso e escore de condição corporal para serem acasaladas aos 9 meses de idade.

\section{Material e Métodos}

Os dois experimentos foram realizados no período de julho de 2005 a abril de 2006, em área pertencente à Universidade Federal de Santa Maria (UFSM), Rio Grande do Sul (latitude $29^{\circ} 43^{\prime} \mathrm{S}$, longitude $53^{\circ} 42^{\prime} \mathrm{O}$ ).

O clima da região é subtropical úmido, conforme classificação de Köppen (Moreno, 1961), e os valores de temperatura $\left({ }^{\circ} \mathrm{C}\right)$ e precipitação pluviométrica $(\mathrm{mm})$ do período experimental e as respectivas normais climáticas dos últimos 30 anos foram obtidas junto à estação meteorológica da UFSM (Figura 1). O solo é classificado como Argissolo vermelho distrófico arênico, integrante da unidade de mapeamento São Pedro (Embrapa, 1999), e apresentou na análise os seguintes valores médios: $\mathrm{pH}-\mathrm{H}_{2} \mathrm{O}: 5,8$; porcentagem de argila: $23,5 \mathrm{~m} / \mathrm{V}$; fósforo: $6,4 \mathrm{mg} / \mathrm{L}$; potássio: $34 \mathrm{mg} / \mathrm{L}$; porcentagem de matéria orgânica: $2,7 \mathrm{~m} / \mathrm{V}$; alumínio: $0 \mathrm{cmol} / \mathrm{L}$; cálcio: $7,4 \mathrm{cmol} / \mathrm{L}$; magnésio: $4,3 \mathrm{cmol} / \mathrm{L} ; \mathrm{CTC} \mathrm{pH}$ $7: 15,0 \mathrm{cmol} / \mathrm{L}$.
No experimento 1 , avaliou-se o fornecimento de suplemento (níveis 0,$0 ; 0,5 ; 1,0$ ou $1,5 \%$ do peso vivo) a ovelhas e cordeiras nos períodos pré e pós-desmame em pastagem de azevém (Lolium multiflorum Lam.) e, no experimento 2, esses mesmos níveis de suplemento a cordeiras em pastagem de milheto (Pennisetum americanum L. Leeke). Em ambos os experimentos, os animais tiveram livre acesso a água e sal mineral.

As pastagens de azevém (Lolium multiflorum Lam.) e de milheto (Pennisetum americanum (L.) Leeke) foram estabelecidas por meio de preparo convencional do solo $(23 / 6 / 2005)$ e semeadura a lanço $(25 / 11 / 2005)$. Na pastagem de azevém, foram utilizados $40 \mathrm{~kg} / \mathrm{ha}$ de semente e a adubação consistiu de $200 \mathrm{~kg} / \mathrm{ha}$ da fórmula 5-20-20 mais $50 \mathrm{~kg} / \mathrm{ha}$ de cloreto de potássio (0-0-60). Em cobertura, foi adicionado nitrogênio $(\mathrm{N})$ na forma de ureia $(45 \mathrm{~kg} / \mathrm{ha}$, divididos em duas aplicações: 20/7 e 5/9/2005). Na pastagem de milheto, foram utilizados $30 \mathrm{~kg} / \mathrm{ha}$ de semente, com $250 \mathrm{~kg} / \mathrm{ha}$ de adubo N-P-K, fórmula 05-20-20, e, em cobertura, foram adicionados $100 \mathrm{~kg} / \mathrm{ha} \mathrm{de} \mathrm{N}$, na forma de ureia, em quatro aplicações (2/1, 6/2, 17/2 e 23/3/2006). A área experimental utilizada apresentava um banco de sementes de capim-papuã (Urochloa plantaginea), o que ocasionou a presença dessa espécie na pastagem durante o experimento com milheto.

A área experimental foi subdividida em oito piquetes de 0,2 e 0,07 ha nos experimentos 1 e 2 , respectivamente, que constituíram as unidades experimentais. Foram usadas 24 cordeiras-teste, mestiças Ile de France e Texel, com 46 dias de idade $(14,7 \pm 3,9 \mathrm{~kg})$ no início do experimento 1 e com seis meses e meio de idade $(27,4 \pm 3,6 \mathrm{~kg})$ no experimento 2 . As

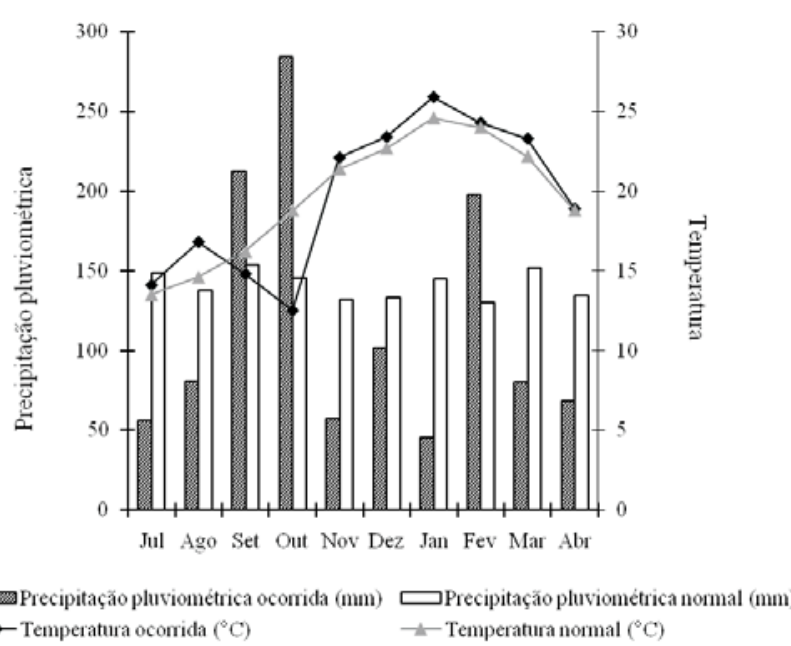

Figura 1 - Médias mensais de temperatura $\left({ }^{\circ} \mathrm{C}\right)$ e precipitação pluviométrica $(\mathrm{mm})$ e normais climáticas do período de 1961 a 1990 
cordeiras foram sorteadas nos tratamentos respeitando a ordem de nascimento e a categoria das mães (primíparas e multíparas).

O método de pastejo foi o de lotação contínua, com taxa de lotação variável. Os animais eram mantidos nos piquetes das 8 às $17 \mathrm{~h} 30 \mathrm{e}$, no período noturno, eram retirados da pastagem e estabulados. Os animais foram submetidos a um período de 11 dias de adaptação aos níveis de suplemento. O suplemento utilizado foi ração comercial, composta de farelo de trigo, farelo de soja, casca de aveia moída, refinazil, calcário calcítico, fosfato bicálcico, cloreto de sódio e premix vitamínico, com $16,3 \%$ de proteína bruta, $25,8 \%$ de fibra em detergente neutro e $61,2 \%$ de nutrientes digestíveis totais, fornecido em conjunto (ovelhas+cordeiras), diariamente às $14 \mathrm{~h}$.

$\mathrm{O}$ experimento 1 foi dividido em dois períodos de avaliação: de 12/9 a 7/10/2005 com as cordeiras ao pé da mãe, e de $8 / 10$ a 28/10/2005, com as cordeiras já desmamadas. $O$ desmame foi realizado quando as cordeiras apresentaram peso mínimo de $18 \mathrm{~kg}$ e idade média de 60 dias.

Do dia 29/10/2005 até 1/2/2006, após o experimento 1 e até o início do experimento 2 , as cordeiras foram mantidas em pastagem nativa sem suplemento. Durante 96 dias de utilização, o campo nativo apresentou massa de forragem e taxa de acúmulo de forragem de $3.000 \mathrm{~kg} / \mathrm{ha}$ de matéria seca e $15 \mathrm{~kg} / \mathrm{ha}$ de $\mathrm{MS} / \mathrm{dia}$, respectivamente. O pasto aparentemente consumido pelos animais apresentou 13,6\% de proteína bruta, $62,9 \%$ de fibra em detergente neutro e $60,3 \%$ de nutrientes digestíveis totais.

No experimento 2, as cordeiras permaneceram em pastagem de milheto (Pennisetum americanum L. Leeke) do dia $2 / 2$ ao dia 7/4/2006, totalizando 64 dias de pastejo. $\mathrm{O}$ suplemento foi fornecido diariamente às $17 \mathrm{~h}$, em baias individuais, e consistiu de ração comercial, composta de farelo de arroz, farelo de trigo, farelo de soja, casca de arroz moída, calcário calcítico, fosfato bicálcico, cloreto de sódio, premix vitamínico mineral (19,8\% proteína bruta; $19,7 \%$ fibra em detergente neutro e $86,9 \%$ de nutrientes digestíveis totais).

Em ambos os experimentos, a massa de forragem ( $\mathrm{kg} / \mathrm{ha}$ de MS) foi avaliada a cada dez dias por meio da técnica de estimativa visual com dupla amostragem, com 20 estimativas visuais e cinco cortes rente ao solo em área de $0,25 \mathrm{~m}^{2}$. Nessa ocasião, em 20 pontos por piquete, a altura do pasto foi medida com régua graduada em centímetros. A forragem proveniente dos cortes foi homogeneizada e dividida em duas subamostras, uma para determinação do teor de MS do pasto e outra para separação dos componentes botânicos e estruturais. A partir dessas amostras, foram calculadas a participação, em percentual, de lâminas foliares e colmos e a relação proporcional entre esses componentes. O percentual de material verde na pastagem multiplicado pela massa de forragem resultou na massa de forragem verde. No experimento 1 , foi medida a altura do pseudocolmo desde o solo até a lígula da última folha expandida e, por meio dessa medida, foi calculada a profundidade de lâminas foliares $(\mathrm{cm})$, pela diferença entre a altura do dossel e a altura do pseudocolmo.

As perdas de forragem foram avaliadas conforme metodologia descrita por Hillesheim \& Corsi (1990). Para determinação da taxa de acúmulo de forragem $(\mathrm{kg} / \mathrm{ha} / \mathrm{dia}$ de MS), foram utilizadas três gaiolas de exclusão ao pastejo por piquete. A disponibilidade diária de forragem $(\mathrm{kg} / \mathrm{ha} /$ dia de MS) foi obtida pela soma da taxa de acúmulo de forragem com a massa de forragem do período, dividida pelo número de dias do período. A razão entre a disponibilidade diária de forragem e a carga animal (peso médio dos animais-teste + peso médio de cada animal regulador*número de dias no piquete/número de dias do período), multiplicada por 100 , resultou na oferta de forragem, que, multiplicada pelo percentual de lâminas foliares na massa de forragem, deu origem à oferta de lâminas foliares verdes.

A simulação de pastejo (Euclides et al., 1992) foi realizada a cada 21 dias, por meio da observação do hábito de pastejo e da preferência dos animais pelas espécies, e da coleta manual de uma amostra de aproximadamente $0,5 \mathrm{~kg}$ de forragem em cada repetição. As amostras foram pesadas e secas em estufa com circulação forçada de ar a $55^{\circ} \mathrm{C}$ por 72 horas, pesadas novamente e moídas em moinho tipo Willey com peneira de $1 \mathrm{~mm}$. As amostras foram acondicionadas em sacos plásticos e utilizadas posteriormente para determinação da digestibilidade in vitro da matéria orgânica (Tilley \& Terry, 1963), da fibra em detergente neutro (Robertson \& Van Soest, 1981), com utilização de sacos de poliéster conforme modificação de Komarek (1993), e de nutrientes digestíveis totais (Kunkle \& Bates, 1998). O teor de proteína bruta foi obtido pelo método Kjeldahl (AOAC, 1995).

A cada 21 dias, realizaram-se a pesagem dos animais, após jejum de sólidos e líquidos de 12 horas, e as avaliações do escore de condição corporal, por palpação da região lombar, atribuindo-se valores de 1 (muito magro) a 5 (muito gordo) (Pereira Neto, 2004). O ganho médio diário das cordeiras foi obtido pela diferença de peso dos animais entre as pesagens dividido pelo número de dias do período. A taxa de lotação foi calculada pela divisão da carga animal (kg/ha de PV) por 20 e $30 \mathrm{~kg}$ (valores médios do peso dos animais-teste nos experimentos 1 e 2 , respectivamente) e expressa em número de animais por hectare. Para o cálculo 
do ganho de peso corporal por área, a taxa de lotação foi multiplicada pelo ganho médio diário dos animais-teste.

Na pastagem de azevém, o consumo diário de forragem, expresso em \% do PC, foi calculado pelo método agronômico (Woodward, 1936), por meio da divisão do desaparecimento de forragem pela carga animal e multiplicado por 100 e, na pastagem de milheto, pelo método indireto, com a utilização de óxido crômico (Pond et al., 1989) como marcador externo.

O delineamento experimental foi o inteiramente casualizado, com parcelas subdivididas no tempo, com quatro tratamentos e duas repetições de área. Os dados foram submetidos à análise de variância pelo procedimento General Linear Model, testes de correlação, regressão polinomial e estudo de contrastes a 5\% de significância. As variáveis que não apresentaram interações significativas e não se ajustaram aos modelos de regressão testados foram submetidas ao teste Tukey a $5 \%$ de probabilidade. Para o peso vivo, foi realizada análise de contraste entre animais sob suplementação e aqueles sem suplementação, usando dados dos experimentos 1 e 2. As análises foram feitas com o auxílio do programa estatístico SAS v.8.02 (2001), de acordo com o seguinte modelo matemático geral:

$$
\gamma_{i j k}=\mu+\tau_{i}+\alpha_{j}+(\tau \alpha)_{i j}+\lambda_{k}\left(\tau_{i}\right)+\varepsilon_{i j k}
$$

em que: $\gamma_{i j k}=$ variáveis-dependentes; $\mu=$ média de todas as observações; $\tau_{\mathrm{i}}=$ efeito do i-ésimo nível de suplemento; $\alpha_{\mathrm{j}}=$ efeito do j-ésimo período; $(\tau \alpha)_{\mathrm{ij}}=$ interação entre o nível de suplemento e o j-ésimo período; $\lambda_{\mathrm{k}}\left(\tau_{\mathrm{i}}\right)=$ efeito da k-ésima repetição dentro do i-ésimo nível de suplemento; $\varepsilon_{\mathrm{ijk}}=$ erro experimental residual.

\section{Resultados e Discussão}

Na pastagem de azevém, não houve interação $(\mathrm{P}>0,05)$ níveis de suplemento e dias de utilização da pastagem para o ganho médio diário. Os níveis de suplemento influenciaram $(\mathrm{P}<0,05)$ o ganho médio diário das cordeiras ao pé da mãe e o valor médio desses ganhos em todo o ciclo do azevém, sem ajuste a nenhum modelo de regressão (Tabela 1).

Tabela 1 - Desempenho de cordeiras ao pé da mãe e após a desmama em pastagem de azevém recebendo suplemento (experimento 1)

\begin{tabular}{lccccc}
\hline Fase & \multicolumn{5}{c}{ Nível de suplemento $(\%)$} \\
\cline { 2 - 6 } & Sem suplemento & 0,5 & 1,0 & 1,5 & Média \\
\hline Ao pé da mãe & $188 \mathrm{~b}$ & $287 \mathrm{a}$ & $206 \mathrm{~b}$ & $263 \mathrm{a}$ & $236 \mathrm{~A}$ \\
Pós-desmame & $38^{\mathrm{ns}}$ & 44 & 48 & 53 & $46 \mathrm{~B}$ \\
Média & $113 \mathrm{~b}$ & $166 \mathrm{a}$ & $127 \mathrm{~b}$ & $158 \mathrm{a}$ & 141 \\
\hline
\end{tabular}

Médias seguidas de letras minúsculas distintasna coluna diferem $(\mathrm{P}<0,05)$ pelo teste Tukey.

Médias seguidas de letras maiúsculas distintas na linha diferem $(\mathrm{P}<0,05)$ pelo teste Tukey.

${ }^{\text {ns }}$ Não-significativo a $5 \%$ de probabilidade.
O consumo de matéria seca e o desempenho de animais em pastejo são fortemente influenciados pela disponibilidade de forragem (Hodgson, 1990). Os valores médios de massa de forragem e oferta de forragem (Tabela 2), conforme Mott (1984) e Hodgson (1981), indicam que não ocorreu restrição ao consumo de pasto pelos animais. O manejo da pastagem possibilitou manter a mesma massa de forragem verde $(\mathrm{P}>0,05)$ nos períodos avaliados, portanto a diferença nos valores de massa de forragem e oferta de forragem entre as avaliações deve-se à presença mais acentuada de colmos e material senescente na pastagem, em decorrência do estádio reprodutivo do azevém (Tabela 2 ).

O ganho médio diário das cordeiras ao pé da mãe pode ser atribuído à disponibilidade de pasto, à quantidade de suplemento consumida e à habilidade materna das ovelhas. O leite é responsável por $25 \%$ da energia ingerida por cordeiros lactentes (Carvalho, 2004) e o consumo de energia por ovelhas em lactação tem importante efeito na produção e na qualidade do leite (Wilson et al., 1971). Nesta pesquisa, as ovelhas mantiveram o peso vivo durante a lactação, portanto, o consumo de energia proveniente da forragem + suplemento provavelmente foi suficiente para manter o metabolismo basal das ovelhas e produção de leite adequada para promover o ganho médio diário observado nos níveis de suplemento oferecidos às cordeiras.

O ganho de peso foi similar entre os níveis de suplemento de 0,5 e $1,5 \%$ do PV e foi maior que o obtido com os outros níveis (Tabela 1), fato que confirma os resultados obtidos por Hatfield et al. (1995) de que o consumo de alimentos sólidos durante o aleitamento influencia positivamente o ganho de peso. A alternativa de fornecimento de suplemento a cordeiros a partir da terceira semana de vida pode complementar o fornecimento energético e proteico do leite materno, que tende a diminuir com o avanço da lactação (Villas Bôas et al., 2003). As cordeiras recebendo suplemento na proporção de $1 \%$ do PV, no entanto, apresentaram ganho similar ao daquelas sem suplementação. Esse desempenho similar (Tabela 1) pode também ter sido influenciado pela forma de suplementação, não-individualizada, pois, quando animais de diferentes categorias (ovelhas e cordeiras) são suplementados em conjunto, a quantidade-alvo de suplemento a ser consumida normalmente não é alcançada, em razão da concorrência pelo alimento, que é agravada pela dominância entre os animais (Bowman \& Sowell, 1997). Assim, o desempenho das cordeiras pode ter sido influenciado também por fatores comportamentais, e não apenas pela quantidade extra de nutrientes fornecida pelo suplemento. $\mathrm{O}$ ganho médio pré-desmama (Tabela 1) está dentro do valorlimite de 200 g, considerado por Siqueira (2000) como o ganho mínimo econômico para cordeiros em confinamento. 
Tabela 2 - Características estruturais e bromatológicas de uma pastagem de azevém com cordeiras ao pé da mãe e após a desmama, sob suplementação

\begin{tabular}{|c|c|c|c|}
\hline \multirow[t]{2}{*}{ Item } & \multicolumn{2}{|c|}{ Período } & \multirow[t]{2}{*}{ Média } \\
\hline & Ao pé da mãe & Desmamadas & \\
\hline Massa de forragem ( $\mathrm{kg} / \mathrm{ha}$ de $\mathrm{MS})$ & $1285,5 b$ & $1657,2 \mathrm{a}$ & $1471,3 \pm 79$ \\
\hline Massa de forragem verde ( $\mathrm{kg} / \mathrm{ha}$ de $\mathrm{MS})$ & 1056,7 & 1062,5 & $1059,6 \pm 73$ \\
\hline Massa de lâminas foliares ( $\mathrm{kg} / \mathrm{ha}$ de $\mathrm{MS})$ & $668,6 \mathrm{a}$ & $132,3 b$ & $400,4 \pm 28$ \\
\hline Altura do pasto $(\mathrm{cm})$ & $14,4 \mathrm{~b}$ & $18,9 \mathrm{a}$ & $16,6 \pm 0,6$ \\
\hline Oferta de forragem ( $\mathrm{kg} \mathrm{MS} / 100 \mathrm{~kg} \mathrm{PV})$ & $11,9 b$ & $17,7 \mathrm{a}$ & $14,8 \pm 1,5$ \\
\hline Oferta de lâminas foliares verdes ( $\mathrm{kg} \mathrm{MS} / 100 \mathrm{~kg} \mathrm{PV})$ & $6,2 \mathrm{a}$ & $1,4 \mathrm{~b}$ & $3,8 \pm 0,6$ \\
\hline Relação folha:colmo (kg/kg) & $1,8 \mathrm{a}$ & $0,2 \mathrm{~b}$ & $1,0 \pm 0,08$ \\
\hline Profundidade de lâminas foliares ( $\mathrm{cm}$ ) & $6,4 \mathrm{a}$ & $4,2 b$ & $5,3 \pm 0,2$ \\
\hline Perdas de forragem $(\mathrm{kg} / \mathrm{ha} /$ dia de $\mathrm{MS})$ & $0,5 b$ & $4,6 \mathrm{a}$ & $2,6 \pm 0,5$ \\
\hline Proteína bruta $(\%)$ & $18,9 \mathrm{a}$ & $16,5 b$ & $17,7 \pm 0,5$ \\
\hline Fibra em detergente neutro $(\%)$ & 46,2 & 51,0 & $48,6 \pm 1,0$ \\
\hline
\end{tabular}

Médias seguidas de letras minúsculas distintas na linha diferem $(\mathrm{P}<0,05)$ pelo teste Tukey.

Após a desmama, o ganho médio diário foi semelhante para todas as cordeiras, independentemente do nível de suplementação, e o valor médio reduziu $81 \%$ em relação ao do período anterior. Essa redução foi, em parte, resultado do estresse natural provocado pela desmama, pois não há coerência entre o ganho de peso observado, as exigências da categoria (NRC, 2006) e a quantidade teórica de nutrientes fornecidos pelo pasto ou pasto+suplemento. A estrutura do dossel, com baixa relação folha:colmo (Tabela 2) também pode ter sido inadequada para animais recém-desmamados. Em resposta à quantidade de nutrientes consumidos, o ganho deveria ter sido maior.

Desmamar cordeiras antes das 14-16 semanas de idade é uma prática de manejo que visa à utilização das pastagens cultivadas de inverno, de maior custo, só com os animais jovens, uma vez que, após a desmama, as ovelhas podem ser mantidas em campo nativo, com menor ingestão de nutrientes. Mesmo com o desempenho reduzido nas cordeiras, conforme descrito por Jordon \& Marten (1968), esperava-se que, na pastagem cultivada, houvesse maior produção por área de produto comercializável. O período de 28 dias pósdesmama na pastagem de azevém não foi suficiente para a total recuperação do estado imunofisiológico e manifestação do potencial genético de ganho de peso das cordeiras. Poli et al. (2008) observaram que cordeiros mantidos com suas mães em pasto de capim-tifton 85 tiveram diferença inferior a dez dias para atingir o mesmo peso que cordeiros desmamados e mantidos em confinamento. Neste experimento, mesmo sob suplementação, as cordeiras apresentaram baixo ganho de peso, o que confirma que o manejo de desmama é mais crítico no desenvolvimento das cordeiras que o fornecimento de suplementos. Poppi \& McLennan (1995), no entanto, afirmaram que a perda de peso pelo estresse da desmama pode ser reduzida com o fornecimento de algum alimento concentrado.
A estrutura da pastagem de azevém teve importante contribuição no ganho de peso das cordeiras no período pós-desmama. A participação de lâminas reduziu $80 \%$ em relação ao período anterior (Tabela 2), determinando relação folha:colmo extremamente baixa. A altura do pasto, em estádio reprodutivo, foi $36 \%$ superior àquela que aumenta o ganho de peso em animais dessa categoria (Carvalho et al., 2006). Assim, a pequena participação de lâminas foliares na massa de forragem, juntamente com a maior altura de pseudocolmo, que ocasionou menor profundidade de folhas na estrutura vertical da pastagem (Tabela 2), pode ter agravado a perda de peso das cordeiras.

Não houve interação níveis de suplemento $\times$ dias de utilização da pastagem para o escore de condição corporal (ECC) das cordeiras $(\mathrm{P}>0,05)$. Ao final da utilização da pastagem de azevém, o valor do ECC não foi influenciado pelos níveis de suplemento e apresentou valor médio de 3,9 pontos. A condição corporal reflete as reservas energéticas dos animais e depende do seu estágio de desenvolvimento. Nessa fase de desenvolvimento das cordeiras, o ganho de peso é convertido quase que exclusivamente em massa muscular, portanto, somente em animais próximos à maturidade sexual, o escore de condição corporal é influenciado pela dieta (Owens et al., 1995).

Não houve interação níveis de suplemento $\times$ dias de utilização da pastagem de azevém $(\mathrm{P}>0,05)$ para o ganho de peso por área e para a taxa de lotação. Os níveis de suplemento testados não tiveram efeito sobre a taxa de lotação $(\mathrm{P}>0,05)$, mas influenciaram o ganho de peso por área $(\mathrm{P}<0,05)$, que não se ajustou a nenhum modelo de regressão (Tabela 3 ).

Para taxa de lotação semelhante (Tabela 3), não foi verificada substituição do consumo de matéria seca do pasto pelo consumo de matéria seca do suplemento, efeito mais comumente registrado na bibliografia quando os animais recebem suplemento em pastagens hibernais 
Tabela 3 - Taxa de lotação e ganho de peso por hectare de cordeiras em pastagem de azevém sob suplementação (experimento 1)

\begin{tabular}{lccccc}
\hline & \multicolumn{5}{c}{ Nível de suplemento $(\%)$} \\
\cline { 2 - 6 } & Sem suplemento & 0,5 & 1,0 & 1,5 & Média \\
\hline $\begin{array}{l}\text { Ganho peso área } \\
\text { (kg/ha de PC) }\end{array}$ & $72,9 \mathrm{~b}$ & $99,7 \mathrm{a}$ & $85,0 \mathrm{a}$ & $102,7 \mathrm{a}$ & 90,1 \\
$\begin{array}{l}\text { Taxa lotação } \\
\text { (cab/ha) }\end{array}$ & $19,3^{\text {ns }}$ & 26,4 & 23,2 & 23,9 & 23,2 \\
\hline
\end{tabular}

Médias seguidas de letras minúsculas distintas na coluna diferem $(P<0,05)$ pelo teste Tukey.

ns Não-significativo a $5 \%$ de probabilidade.

(Rearte \& Pierone, 2001). A semelhança $(\mathrm{P}>0,05)$ nas taxas de acúmulo e de perdas de forragem entre os níveis de suplemento resultou em número semelhante de animais para manter a massa de forragem e a oferta de forragem iguais entre os níveis de suplemento.

O ganho de peso por área foi maior entre os animais sob suplementação, independentemente do nível ( $\mathrm{P}>0,05)$, como reflexo do ganho médio diário dos animais ao longo do período de pastejo. Em pastagem de azevém, o uso de suplementos provocou aumento de 23,9\%, em média, no ganho de peso por área. Essa medida é o principal parâmetro para estimar a lucratividade do sistema de produção adotado e a economicidade do uso de suplemento depende do seu custo adicional em relação ao acréscimo na renda da atividade (Rocha et al., 2003).

Na pastagem de milheto, não houve interação entre níveis de suplemento e dias de utilização da pastagem $(\mathrm{P}>0,05)$ para o ganho médio diário, o escore de condição corporal, o ganho de peso por área e a taxa de lotação. Essas variáveis apresentaram diferença $(\mathrm{P}<0,05)$ apenas na análise de contraste entre animais sem suplementação e aqueles que receberam suplemento (Tabela 4).

O ganho médio diário das cordeiras sob suplementação aumentou 44\% em relação ao daquelas que não receberam suplemento. Montagner et al. (2002), avaliando o desempenho de cordeiras sob pastejo rotativo em pastagem de milheto sem suplementação, observaram ganho médio diário de $66 \mathrm{~g} /$ dia e atribuíram esse baixo desempenho à pequena disponibilidade de lâminas foliares e à alta disponibilidade de colmos na pastagem (relação folha:colmo de 0,9$)$. A relação folha:colmo média no milheto neste estudo foi de 0,3 (Tabela 5) e o ganho médio diário das cordeiras que não receberam suplemento foi semelhante ao relatado por Montagner et al. (2002), de $54 \mathrm{~g} / \mathrm{dia}$.

A oferta de forragem foi, em média, quatro vezes maior que a necessária para atender às exigências de ingestão de matéria seca recomendada pelo NRC (2006) para o ganho diário médio pelas cordeiras. Rattray et al. (1987) encontraram relação quadrática e positiva entre oferta de forragem e o ganho médio diário com ponto máximo de $0,100 \mathrm{~kg} /$ dia em oferta de forragem de $10 \%$, o que indica que o desempenho dos animais no experimento 2 poderia ter sido prejudicado pela elevada oferta de forragem, com estrutura do pasto desfavorável ao pastejo de ovinos.

$\mathrm{O}$ valor médio de massa de forragem observado na pastagem de milheto foi inferior a $2.000 \mathrm{~kg} / \mathrm{ha}$ de $\mathrm{MS}$ (Tabela 5), considerado limite mínimo de forragem disponível em pasto de gramíneas tropicais para não restringir a ingestão de matéria seca pelos animais (Minson, 1990). Essas pastagens têm como características a baixa densidade de forragem e a alta dispersão espacial de folhas, que podem dificultar o processo de ingestão de MS pelos animais em pastejo, em decorrência do aumento do tempo necessário para a formação do bocado (Carvalho et al., 2001).

Considerando a oferta de lâminas foliares verdes, $24,13 \%$ da oferta de forragem (Tabela 5), conclui-se que a pastagem de milheto não apresentava a disponibilidade de lâminas foliares necessária para que as cordeiras consumissem forragem suficiente para atender suas necessidades de matéria seca. Conforme descrito por Prache \& Peyraurd (1997), a estrutura oferecida ao animal em pastejo influencia o consumo, pois a qualidade da dieta não depende somente do potencial qualitativo da pastagem, mas também da possibilidade e capacidade do animal em selecionar uma dieta de alto valor nutritivo.

As taxas de lotação diferiram $(\mathrm{P}<0,05)$ entre a pastagem exclusiva e aquela com suplementação (Tabela 4). A superioridade da taxa de lotação está relacionada ao peso mais elevado dos animais sob suplementação ao longo do ciclo do milheto, já que praticamente não houve a utilização de animais adicionais aos animais-teste para ajuste da massa de forragem. Nas cordeiras que receberam

Tabela 4 - Probabilidade de contraste entre cordeiras em pastagem de milheto (experimento 2) com ou sem suplementação e valores médios de taxa de lotação, ganho médio diário, ganho de peso por hectare e escore de condição corporal

\begin{tabular}{lcc}
\hline Item & Não-suplementada & Suplementada \\
\hline Ganho médio diário (g/dia) & 54 & 96 \\
Escore de condição corporal (pontos) & 3,00 & 3,5 \\
Ganho de peso por área (kg/ha de PV) & 145,6 & 237,3 \\
Taxa de lotação (animal/ha) & 35,9 & $\mathrm{P}=0,0308$ \\
\hline
\end{tabular}


Tabela 5 - Características estruturais e bromatológicas da pastagem de milheto com cordeiras sob suplementação

\begin{tabular}{lr}
\hline Item & Média \\
\hline Massa de forragem (kg/ha de MS) & $1518,5 \pm 318,99$ \\
Altura do pasto (cm) & $17,83 \pm 9,12$ \\
Oferta de forragem (kg MS/100 kg PV) & $15,54 \pm 5,35$ \\
Oferta de lâminas foliares verdes (kg MS/100 kg PV) & $3,75 \pm 1,71$ \\
Relação folha:colmo (kg/kg) & $0,31 \pm 0,15$ \\
Taxa de acúmulo diário de forragem (kg/ha/dia MS) & $119,16 \pm 85,99$ \\
Proteína bruta (\%) & $19,98 \pm 1,72$ \\
Fibra detergente neutro (\%) & $50,01 \pm 5,55$ \\
\hline
\end{tabular}

suplemento, o ganho de peso por área foi $38,6 \%$ superior ao daquelas em pastagem de milheto sem suplementação, como resposta ao melhor desempenho dos animais sob suplementação e da maior taxa de lotação. Apesar de ter sido maior entre os animais sob suplementação, o ganho por área ficou $47 \%$ abaixo da produção potencial da pastagem de milheto para utilização com bovinos, de 7,0 kg/ha de peso vivo por dia (Moraes \& Maraschin, 1988).

O escore de condição corporal não foi influenciado pelos níveis de suplemento $(\mathrm{P}>0,05)$ e apresentou diferença significativa apenas entre animais sem suplementação e aqueles que receberam suplemento (Tabela 4). Nos animais que receberam suplemento, o maior ganho médio diário foi acompanhado de maior percentual de gordura corporal, medido pelo escore de condição corporal, pois o aumento do peso, concomitantemente com a idade, aumenta a proporção de gordura e diminui, proporcionalmente, a de água, proteína e minerais no corpo das cordeiras (Resende et al., 2005).

Segundo Simplício \& Santos (2005), o escore de condição corporal é um importante parâmetro para se definir animais aptos à reprodução quando se objetiva maior eficiência reprodutiva. Embora os níveis de suplemento oferecidos tenham sido crescentes, todas as cordeiras alcançaram escores de condição corporal maiores que 2,5, ou seja, valor adequado para o acasalamento (Gunn et al., 1984).

Os níveis de suplemento não afetaram $(\mathrm{P}>0,05)$ o peso vivo à desmama, o peso vivo final em pastagem de azevém, o peso vivo inicial em pastagem de milheto e o peso corporal final em pastagem de milheto.

Houve diferença ( $\mathrm{P}=0,0351$; Figura 2$)$ apenas no peso corporal das cordeiras sob suplementação em relação àquelas que não receberam suplemento no período final da utilização da pastagem de milheto.
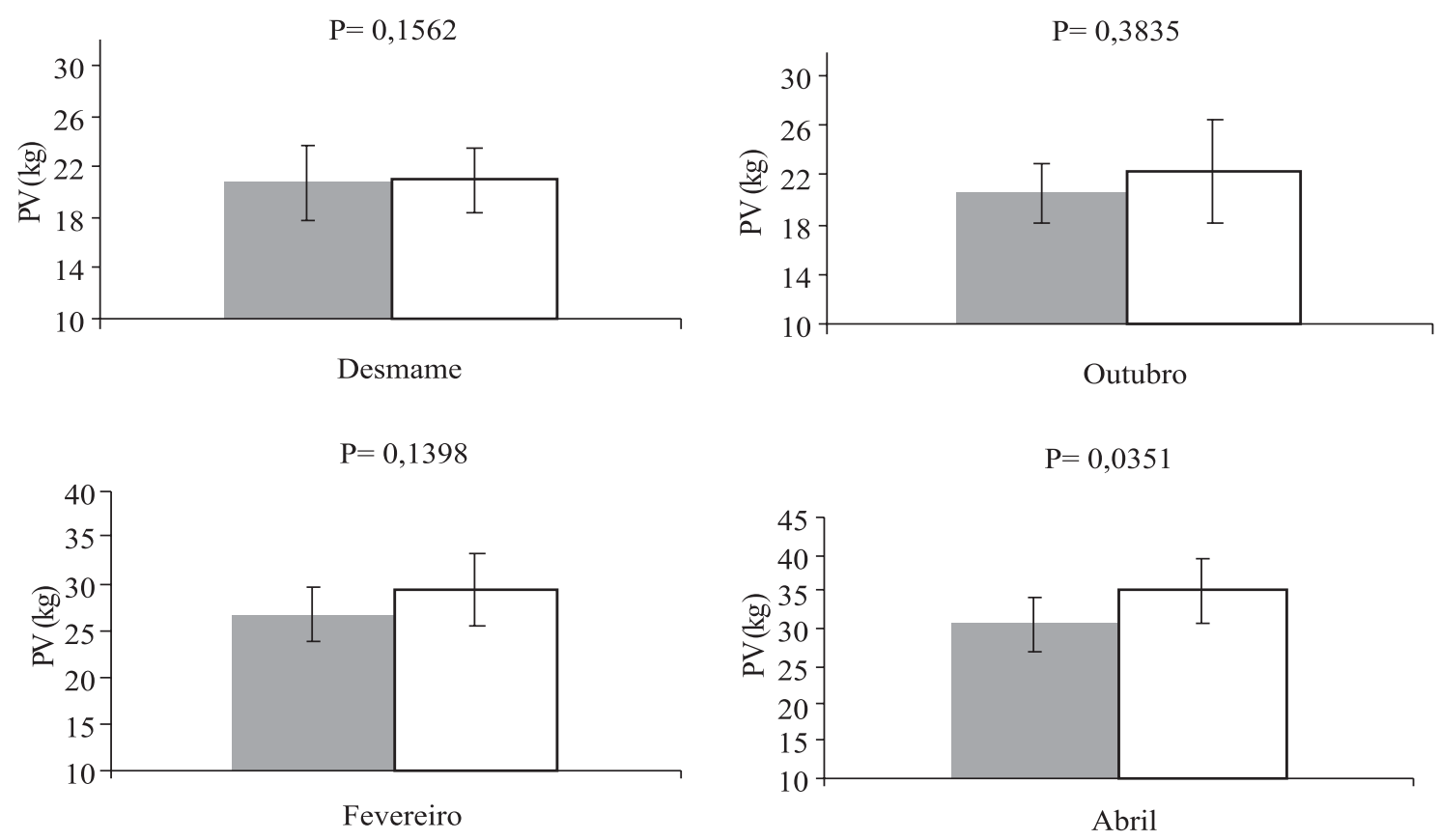

Figura 2 - Peso corporal $(\mathrm{kg})$ de cordeiras sob suplementação (colunas sem preenchimento) e sem suplementação (colunas com preenchimento) em pastagens de azevém e milheto. 
O peso corporal das cordeiras no final do ciclo do azevém representou $47,4 \%$ do seu peso adulto $(50 \mathrm{~kg})$ e, para ser encarneiradas no início de abril, as cordeiras necessitariam de ganho de peso próximo a $74 \mathrm{~g} /$ dia durante os meses de novembro a março.

As cordeiras sob suplementação apresentaram, ao final do período de utilização da pastagem de milheto, maior peso corporal ( $70,2 \%$ do peso adulto) em comparação àquelas que não receberam suplemento e esse maior peso corporal foi suficiente para o encarneiramento aos 9 meses de idade. As cordeiras mantidas exclusivamente em pastagem apresentaram $61,2 \%$ do peso adulto ao final da pastagem de milheto e não atingiram o peso mínimo para encarneiramento, de $65 \%$ do peso adulto (Otto de Sá \& Sá, 2006).

\section{Conclusões}

A estrutura da pastagem de azevém e de milheto pastejada por cordeiras não é influenciada pela suplementação e as mudanças no pasto dependem do ciclo das espécies. A utilização da pastagem de azevém por cordeiras nos períodos pré e pós-desmama, associada ao fornecimento de suplemento em níveis de 0,5 a $1,5 \%$ do peso vivo, permite que atinjam peso e escore de condição corporal adequados para o acasalamento aos 9 meses de idade.

\section{Referências}

ANUALPEC. Anuário da pecuária brasileira. 13.ed. São Paulo: Instituto FNP, 2006. 369p.

ASSOCIATION OF OFFICIAL ANALYTICAL CHEMISTRY. Official methods of analysis. 16.ed. Washington: AOAC International, 1995. 1094p.

BOWMAN, JGP.; SOWELL, B.F. Delivery method and supplement consumption by grazing ruminants: a review. Journal of Animal Science, v.75, p.543-550, 1997.

CARVALHO, P.C.F.; OLIVEIRA, J.O.R.; PONTES, L.S. et al. Características de carcaça de cordeiros em pastagem de azevém manejada em diferentes alturas. Pesquisa Agropecuária Brasileira, v.41, n.7, p.1193-1198, 2006.

CARVALHO, P.C.F. Exigências de forragem disponível para ovinos em pastagens. In: PEREIRA NETO, O.A.; MÔRLAN, J.B.; CARVALHO, P.C.F. et al. (Eds.). Práticas em ovinocultura: ferramentas para o sucesso. Porto Alegre: SENAR/RS, 2004. p.29-38.

CARVALHO, P.C.F.; MARCAL, G.K.; RIBEIRO FILHO, H.M.N. et al. Pastagens altas podem limitar o consumo dos animais. In: REUNIÃO ANUAL DA SOCIEDADE BRASILEIRA DE ZOOTECNIA, 38., 2001, Piracicaba. Anais... Piracicaba: Sociedade Brasileira de Zootecnia, 2001. (CD-ROM).

CASTRO, C.R.C. Relações planta-animal em pastagem de milheto (Pennisetum americanum (L.) Leeke.) manejada em diferentes alturas com ovinos. 2002. 200f. Dissertação (Mestrado em Zootecnia) - Universidade Federal do Rio Grande do Sul, Porto Alegre.
COE, A. Observações da produção ovina na região da fronteira do Rio Grande do Sul. Santana do Livramento: Edigraf, 1991. 79p.

EMPRESA BRASILEIRA DE PESQUISA AGROPECUÁRIA EMBRAPA CNPS. Sistema brasileiro de classificação de solos. Brasília: EMBRAPA, 1999. 412p.

EUCLIDES, V.P.B.; MACEDO, M.C.M.; OLIVEIRA, M.P. Avaliação de diferentes métodos de amostragem sob pastejo. Revista Brasileira de Zootecnia, v.21, n.4, p.691-702, 1992.

GUNN, R.G.; DONEY, J.M.; SMITH, W.F. The effect of level of pre-mating nutrition on ovulatory rate in scottish blackface ewes in different body conditions at mating. Animal Production, v.39, p.235-239, 1984.

HATFIELD, P.G.; SNOWDER, G.D.; HEAD JR., W.A. et al. Production by ewes rearing single or twin lambs: effects of dietary crude protein percentage and supplemental zinc methionine. Journal of Animal Science, v.73, p.1227-1238, 1995.

HILLESHEIM, A.; CORSI, M. Capim-elefante sob pastejo: fatores que afetam as perdas e utilização de matéria seca. Pesquisa Agropecuária Brasileira, v.25, n.9, p.1233-1246, 1990.

HODGSON, J. Variations in the surface characteristics of the sward and short-term rate at herbage intake by calves and lambs. Grass and Forage Science, v.36, p.49-57, 1981.

HODGSON, J. Grazing management. Science into practice. England: Longman Scientific and Technical, 1990. 203p.

JORDON, R.M.; MARTEN, G.C. Effect of weaning, age at weaning and grain feeding on the performance and production of grazing lambs. Journal of Animal Science, v.27, n.1, p.174-177, 1968.

KOMAREK, A.R. A filter bag procedure for improved efficiency of fiber analysis. Journal of Dairy Science, v.76, p.250-259, 1993, (supp1.1).

KUNKLE, W.E.; BATES, D.B. Evaluating feed purchasing options: energy, protein, and mineral supplements. In: FLORIDA BEEF CATTle ShORT COURSE, 1998, Gainesville. Proceedings... Gainesville: University of Florida, 1998. p.59-70.

MINSON, D.J. Forage in ruminant nutrition. San Diego: Academic Press, 1990. 483p.

MONTAGNER, D.B.; ROCHA, M.G.; PILAU, A. et al. Desempenho de borregas em pastejo rotativo com milheto. In: REUNIÃO ANUAL DA SOCIEDADE BRASILEIRA DE ZOOTECNIA, 39., 2002, Fortaleza. Anais... Fortaleza: Sociedade Brasileira de Zootecnia, 2002. (CD-ROM).

MORAES, A.; MARASCHIN, G.E. Pressões de pastejo e produção animal em milheto cv. comum. Pesquisa Agropecuária Brasileira, v.2, n.23, p.197-205, 1988.

Moreno, J.A. Clima do Rio Grande do Sul. Porto Alegre: Secretaria da Agricultura, 1961. 41p.

MOTT, G.O. Relationship of available forage and animal performance in tropical grazing systems. In: FORRAGE GRASSLAND CONFERENCE, 1984, Houston. Proceedings... Houston: American Forage and Grassland Council, 1984. p.373-377.

NATIONAL RESEARCH COUNCIL - NRC. Nutrient requirements of sheep. Washington, D.C.: The National Academy Press, 2006. $362 \mathrm{p}$.

OTTO de SÁ, C.; SÁ, J.L.de. [200-]. Estacionalidade reprodutiva e condição corporal de ovinos. Disponível em: <http:// www.crisa.vet.br>. Acesso em: 10/12/2006.

OWENS, F.N.; GILL, D.R.; SECRIST, D.S. et al. Review of some aspects of growth and development of feedlot cattle. Journal of Animal Science, v.73, p.3152-3172, 1995.

PEREIRA NETO, O.A. Escore de condição corporal. Instrumento de tomada de decisão. In: PEREIRA NETO, O.A.; MÔRLAN, J.B.; CARVAlho, P.C.F. et al. (Eds.). Práticas em ovinocultura: ferramentas para o sucesso. Porto Alegre: SENAR/RS, 2004. p.67-78. 
POLI, C.H.E.C.; MONTEIRO, A.L.G.; BARROS, C.S. et al. Produção de ovinos de corte em quatro sistemas de produção. Revista Brasileira de Zootecnia, v.37, n.4, p.666-673, 2008.

POND, K.R.; ELLIS, W.C.; MATIS, J.H. et al. Passage of chromiummordanted and rare earth-labeled fiber: time of dosing kinetics. Journal of Animal Science, v.67, n.4, p.1020-1028, 1989.

POPPI, D.P.; McLENNAN, S.R. Protein and energy utilization by ruminants at pasture. Journal of Animal Science, v.73, n.1, p.278-290, 1995 .

PRACHE, S.; PEYRAUD, J. Préhensiblite de I' herbe pâturée chez lês bovins et lês ovins. INRA Productions Animales, v.10, p.377-390, 1997.

RATTRAY, P.V.; THOMPSON, K.F.; HAWKER, H. et al. Pastures for sheep production. In: NICOL, A.M. (Ed.). Livestock feeding on pasture. Palmerston North: New Zealand Society of Animal Production, 1987. p.89-104. (Occasional publication, 10).

REARTE, D.H.; PIERONI, G.A. Supplementation of temperate pastures. In: INTERNATIONAL GRASSLAND CONGRESS, 19., 2001, São Pedro. Proceedings... São Pedro: Sociedade Brasileira de Zootecnia, 2001. p.679-689.

RESENDE, K.T.; FERNANDES, M.H.M.; TEIXEIRA, I.A.M.A. Exigências nutricionais de caprinos e ovinos. In: REUNIÃO ANUAL DA SOCIEDADE BRAISLEIRA DE ZOOTECNIA, 42., 2005, Goiânia. Anais... Goiânia: Sociedade Brasileira de Zootecnia, 2005. p.114-135.

RIBEIRO, L.A.O.; GREGORY, R.M.; MATTOS, R.C. Prenhez em rebanhos ovinos do Rio Grande do Sul. Revista Ciência Rural, v.32, n.4, p.637-641, 2002.

ROBERTSON, J.B.; VAN SOEST, P.J. The detergent system of analysis. In: JAMES, W.P.T.; THEANDER, O. (Eds.) The analysis of dietary fibre in food. New York: Marcel Dekker, 1981. p.123-158.
ROCHA, M.G.; RESTLE, J.; PILAU, A. et al. Produção animal e retorno econômico da suplementação em pastagem de aveia e azevém. Revista Ciência Rural, v.33, n.3, p.573-578, 2003.

STATISTICAL ANALYSIS SYSTEM - SAS. Statistical analysis system user's guide. Version 8.02. Cary: Statistical Analysis System Institute, 2001. 943p.

SIMPLÍCIO, A.A.; SANTOS, D.O. Manejo reprodutivo de caprinos e ovinos em regiões tropicais. In: REUNIÃO ANUAL DA SOCIEDADE BRAISLEIRA DE ZOOTECNIA, 42., 2005, Goiânia. Anais... Goiânia: Sociedade Brasileira de Zootecnia, 2005. p.149-156.

SIQUEIRA, E.R. Sistemas de confinamento de ovinos para corte do Sudeste do Brasil. In: SIMPÓSIO INTERNACIONAL SOBRE CAPRINOS E OVINOS DE CORTE, 1., 2000, João Pessoa. Anais... João Pessoa: Empresa Estadual de Pesquisa Agropecuária da Paraíba/AS, 2000. p.107-117.

SOUTHAN, E.R.; HULET, C.V.; BOTKIN, P. Factors influencing reproduction in ewe lambs. Journal of Animal Science, v.33, p.1282-1287, 1971.

TILLEY, J.M.; TERRY, R.A. A two-stage technique for the in vitro digestion of forage crops. Journal of British Grassland Society, v.18, p.104-111, 1963.

VILLAS BÔAS, A.S.; ARRIGONI, M.D.B.; SILVEIRA, A.C. et al. Idade à desmama e manejo alimentar na produção de cordeiros superprecoces. Revista Brasileira de Zootecnia, v.32, n.6, p.1969-1980, 2003 (supl. 2).

WILSON, L.L.; VARELA, A.H.; HESS, C.E. et al. Influence of energy level, creep feeding and lactation stage on and lamb growth characters. Journal of Animal Science, v.33, n.3, p.686-690, 1971.

WODDWARD, T.E. The quantities of grass that dairy cows will graze. Journal of Dairy Science, v.19, n.6, p.347-357, 1936. 